\title{
LABORATÓRIO DE BIOMECÂNICA DA ESCOLA DE EDUCAÇÃO FíSICA E ESPORTE DA UNIVERSIDADE DE SÃO PAULO: PASSADO E PRESENTE - ANÁLISE DA SITUAÇÃO ATUAL
}

\author{
Alberto Carlos AMADIO*
}

\section{INTRODUÇÃO}

O Laboratório de Biomecânica da Escola de Educação Física e Esporte da Universidade de São Paulo (EEFEUSP) iniciou suas atividades em outubro de 1988 e apresenta-se hoje como um agente capaz de interagir com a estrutura científico-acadêmica em nivel de graduação (Iniciação Científica) e pós-graduação "stricto sensu" (Mestrado e Doutorado). Portanto, a participação do Laboratório no sistema ensinopesquisa destaca-se não apenas pela contribuição na formação acadêmica e profíssional como também no desenvolvimento do conhecimento científico da Biomecânica aplicada à análise do movimento humano. $O$ projeto de criação do Laboratório teve início em um estudo realizado no periodo de 1963 a 1982, pelo Instituto Alemão de Ciências do Esporte e Escola Superior de Esportes de Colônia. Mediante $o$ convênio Brasil e Alemanha, constituiu-se o projeto de criação do Laboratório, desde a definição de seus planos e metas até a construção do espaço físico. A coordenação desse projeto foi do Prof.Dr. Hartmut Riehle e as seguintes instituições estiveram envolvidas na viabilização do projeto: MEC-DED (Brasília), FUNDUSP (São Paulo), GTZ-BMI-AA (Bonn, RFA) e DSHS-Köln (Colônia, RFA). Os responsáveis pelo desenvolvimento do projeto junto à EEFEUSP foram o Prof.Dr. Moacyr Brondi Daiuto (Diretor) e o Prof.Dr. Hartmut Heinrich Grabert (Professor Catedrático da disciplina Cinesiologia). O projeto de criação do Laboratório descrevia os seguintes objetivos específicos: a) estabelecer um programa permanente de investigação e apoio didático científico para 0 desenvolvimento da Ciência do Esporte na USP; b) por meio da Biomecânica do Esporte, desenvolver projetos dentro de sua área específica de investigação do movimento esportivo em colaboração com o Instituto de Biomecânica de Colônia -DSHS, RFA; e c) desenvolver projetos e outros programas acadêmicos (Seminários, Cursos e outras formas de treinamento de jovens iniciantes à pesquisa) em Biomecânica do Esporte.

Para uma análise da situação atual, diríamos que o Laboratório tem por meta a investigação e análise do movimento humano em suas estruturas básicas relacionadas a atividades esportivas, atividades do cotidiano, bem como atividades da vida do trabalho, observando-se as consequiências para 0 aparelho locomotor humano, tanto em relação ao rendimento como em relação à otimização técnica, e dependência das características específicas das reações do sistema biológico humano. Estuda-se, portanto, as funções de movimento em condições de normalidade ou disfunções patológicas, no contexto das relações interdisciplinares cujas reivindicações científicas exigem métodos e procedimentos próprios para a melhor compreensão do complexo dos parâmetros que compõem esse fenômeno natural - o movimento humano. Participam do grupo de pesquisa: Alberto Carlos Amadio, Professor Titular (MS6) - Coordenador do Laboratório; Marcos Duarte, Professor Assistente Doutor (MS3); Júlio Cerca Serrão, Professor Assistente (MS2) e Márcia Regina de Sá, Técnica de

\footnotetext{
- Coordenador do Laboratório de Biomecânica da Escola de Educação Física e Esporte da Universidade de São Paulo.
} 
Laboratório. Integram ainda o Laboratório alunos de iniciação científica, mestrandos e doutorandos.

\section{DESCRIÇÃO DAS LINHAS DE PESQUISA EM DESENVOLVIMENTO}

\section{$>$ Biomecânica do Esporte}

Interpretação do movimento esportivo, diagnóstico técnico do rendimento e demais funções determinantes da eficiência de movimento. Dedica-se ainda ao estudo de parâmetros funcionais determinantes do rendimento com dependência tecnológica do sistema Pé-calçado-solo.

\section{$>$ Biomecânica da Locomoção} características da estrutura descritiva da locomoção humana segundo indicadores da Biomecânica externa e Biomecânica interna por meio de complexa análise metodológica e com aplicações nas áreas da Reabilitação, Ergonomia e do Desenvolvimento relativo aos padrões de normalidade.

\section{> Biomecânica do Controle Postural}

A análise descritiva do movimento baseia-se nos indicadores cinemáticos obtidos com base na cinemetria, caracterizada pelo procedimento técnico de análise. Apoia-se no estudo e desenvolvimento de modelos ópticofotogramétricos e modelos matemáticos aplicados ao estudo do controle postural em tarefas de equilíbrio e regulação dinâmica do movimento.

\section{Dorças Internas e Modelagem Biomecânica}

Caracteriza-se pela quantificação dos fatores dinâmicos do movimento humano. A partir de variáveis da força reação do solo sincronizadas como a determinação de coordenadas de pontos anatômicos de referência, determina-se com base em modelos matemáticos e por funções da dinâmica inversa a determinação de forças e momentos intersegmentares aplicados ao controle e à simulação do movimento.

\section{Instrumentação aplicada à Biomecânica}

Desenvolvimento de sistemas e produtos adaptados às funções biomecânicas segundo metodologia para análise do movimento considerando-se a adequação à realidade tecnológica em desenvolvimento e do domínio metodológico para uma ciência interdisciplinar de natureza aplicada.

\section{PROJETOS DE PESQUISA ATUAIS E COM FOMENTO INSTITUCIONAL}

$>$ "Avaliação de respostas dinâmicas na análise do andar de indivíduos portadores de diabetes: uma proposta metodológica" (Processo FAPESP 94/2896-9) - Projeto concluído.

$>$ "Sistema para determinação da potência mecânica humana e aferição de cicloergômetros" (Processo PADCT-CNPq Instrumentação no. 620261/95-1) - Projeto concluído.

$>$ "Estudo da locomoção Humana através de procedimentos biomecânicos integrados ao diagnóstico de pacientes diabéticos" (Processo FAPESP no. 98/09992-4), Projeto em desenvolvimento.

$>$ Programa de intercâmbio e cooperação técnico-científico entre 0 Laboratório de Biomecânica da EEFEUSP e a São Paulo Alpargatas S.A., para desenvolvimento do projeto "Avaliação biomecânica de características de calçados esportivos", Projeto em desenvolvimento. 


\section{ATIVIDADES ATUAIS DE ENSINO E DE EXTENSÃO}

Disciplinas da Graduação (Bacharelados em Educação Física e em Esporte)

DFFB-221: Biomecânica I, semestre ideal: terceiro -4 créditos.

D EFB-222: Biomecânica II, semestre ideal: quarto -4 créditos.

Disciplinas da Pós-graduação "strito sensu" (Mestrado e Doutorado)

DEF-5701: Seminários em Biodinâmica do Movimento Humano - Área de concentração Biodinâmica do Movimento -6 créditos.

$>$ EFB-5736: Introdução aos fundamentos biomecânicos - Área de concentração Biodinâmica do Movimento - 8 créditos.

$>$ EFB-5740: Física para Educação Física - Área de concentração Biodinâmica do Movimento 5 créditos.

\section{Curso de Atualização Universitária}

$>$ "Fundamentos Biomecânicos para análise do Movimento humano" - Curso desenvolvido anualmente no mês de novembro com carga horária de 30 horas-aula, com o objetivo de fornecer bases cientificas aos interessados em estudar os princípios do movimento humano $\mathrm{e}$ sua identificação com funções e mecanismos de adaptação ao exercício físico em condições de normalidade e adaptações patológicas, através de aulas teóricas e práticas de Laboratório.

\section{PROGRAMAS DE INTERCÂMBIO CIENTÍFICO}

$>$ Intercâmbio Científico com a Associação Nacional dos Diabéticos - ANAD (Prof.Dr. Fadlo Fraige Filho). Título do Projeto: "Estudo de parâmetros dinâmicos e neuroanatômicos na análise biomecânica da marcha de individuos com diabetes", Programa em desenvolvimento desde 1997.
$>$ Intercâmbio Acadêmico-Científico com o Laboratório de Biomecânica da Universidade do Estado de Santa Catarina - Centro de Educação Física e Desportos CEFID-UDESC (Prof.Dr. Aluisio Otavio Vargas Ávila).Título do Projeto: "Estudo de interação entre o pé e o calçado e suas repercussões na locomoção humana em condições normais e patológicas através de parâmetros biomecânicos $\mathrm{e}$ antropométricos", Programa em desenvolvimento desde 1997.

$>$ Intercâmbio Acadêmico-Científico com a Deutsche Sporthochschule Köln - DSHS Institut für Biomechanik Köln - Alemanha (Prof.Dr. rer nat W. Baumann). Forma de participação: Professor visitante para desenvolver Seminários na Pós-graduação, desenvolvimento de projetos de pesquisa disciplina e oferecimento de estágio para doutorandos com bolsa "sanduíche" Programas em desenvolvimento desde 1995 Agências financiadoras: DAAD-CAPESCNPq.

$>$ Intercâmbio Acadêmico-Científico com a Faculdade de Ciências do Desporto e Educação Física da Universidade do Porto UP - Portugal (Prof.Dr. Antônio Teixeira Marques e Prof.Dr. João Paulo Vilas-Boas). Forma de participação: Professor visitante para desenvolver disciplina "Biomecânica do Desporto" junto ao Programa de Pósgraduação em Ciência do Desporto - Treino de Alto Rendimento, Programa em desenvolvimento desde 1993 - Agência financiadora: UP-USP.

\section{PRÊMIOS CIENTÍFICOS}

$>$ Congratulações da Assembléia Legislativa do Estado de São Paulo, ao Laboratório de Biomecânica da Escola de Educação Física e Esporte da Universidade de São Paulo, publicado no D.O.E. Poder Legislativo 108 (201, p.11-2 em 22/10/98, Requerimento 3061 de 1998, pela implantação de "Sistema diagnóstico para avaliação de respostas dinâmicas na análise do andar de individuos portadores de diabetes" projeto desenvolvido com financiamento FAPESP/CNPq. 
Prêmio INDESP de Literatura Desportiva Ministério do Esporte e Turismo - Instituto Nacional de Desenvolvimento do Desporto, "Estudo Antropométrico do Pé Humano: relaçðes com $o$ crescimento fisico $e$ importância para o desenvolvimento de calçados esportivos." (9o. lugar) Maurício Dominguez Rodriguez.
$>$ Prêmio na Jornada Nacional de Iniciação Científica, realizada na 47a. SBPC Reunião Anual da Sociedade Brasileira para 0 Progresso da Ciência (1995), "Aspectos Biomecânicos da Ginástica Olímpica - 0 rolamento para trás à parada de mãos" (30. lugar), Luís Mochizuki.

$>$ Prêmio Mérito Acadêmico como melhor aluna - turma de formandos de 1995 - Isabel de Camargo Neves Sacco. 